\title{
Baseline frailty status and outcomes important for shared decision-making in older adults receiving transcatheter aortic valve implantation, a prospective observational study
}

\author{
Elisabeth Skaar ${ }^{1,2} \mathbb{D}$. Anja Øksnes ${ }^{1}$. Leslie Sofia Pareja Eide ${ }^{3} \cdot$ Tone Merete Norekvål $^{1,2}$. Anette Hylen Ranhoff ${ }^{2}$. \\ Jan Erik Nordrehaug ${ }^{2}$ - Daniel Edward Forman ${ }^{4}$ - Andreas W. Schoenenberger ${ }^{5} \cdot$ Karl Ove Hufthammer $^{6}$. \\ Karel Kier-Jan Kuiper ${ }^{1} \cdot \varnothing y v i n d ~ B l e i e^{1} \cdot$ Erik Jerome Stene Packer $^{1,2} \cdot$ Jørund Langørgen $^{1} \cdot$ Rune Haaverstad $^{1,2}$. \\ Margrethe Aase Schaufel ${ }^{7}$
}

Received: 12 December 2019 / Accepted: 26 February 2020 / Published online: 19 March 2020

(c) The Author(s) 2020

\begin{abstract}
Aims The objective of this study was to examine baseline frailty status (including cognitive deficits) and important clinical outcomes, to inform shared decision-making in older adults receiving transcatheter aortic valve implantation (TAVI). Methods and results We conducted a prospective, observational study of 82 TAVI patients, recruited 2013 to 2015 , with 2-year follow-up. Mean age was 83 years (standard deviation (SD) 4.7). Eighteen percent of the patients were frail, as assessed with an 8-item frailty scale. Fifteen patients (18\%) had a Mini-Mental Status Examination (MMSE) score below 24 points at baseline, indicating cognitive impairment or dementia and five patients had an MMSE below 20 points. Mean New York Heart Association (NYHA) class at baseline and 6 months was 2.5 (SD 0.6) and 1.4 (SD 0.6), $(p<0.001)$. There was no change in mean Nottingham Extended Activities of Daily Living (NEADL) scale between baseline and 6 months, 54.2 (SD 11.5 ) and 54.5 (SD 10.3) points, respectively, mean difference $0.3(p=0.7)$. At 2 years, six patients $(7 \%)$ had died, four $(5 \%$, $n=79)$ lived in a nursing home, four (5\%) suffered from disabling stroke, and six (7\%) contracted infective endocarditis.

Conclusions TAVI patients had improvement in symptoms and maintenance of activity of daily living at 6 months. They had low mortality and most patients lived in their own home 2 years after TAVI. Complications like death, stroke, and endocarditis occurred. Some patients had cognitive impairment before the procedure which might influence decision-making. Our findings may be used to develop pre-TAVI decision aids.
\end{abstract}

Keywords Aortic stenosis · TAVI · Activity of daily living $\cdot$ Shared decision making $\cdot$ Older adults

Elisabeth Skaar

Elisabeth.skaar@helse-bergen.no

1 Department of Heart Disease, Haukeland University Hospital, Postboks 1400, 5021 Bergen, Norway

2 Department of Clinical Science, University of Bergen, Bergen, Norway

3 Institute of Health and Social Science, Western Norway University of Applied Sciences, Bergen, Norway

4 Section of Geriatric Cardiology, University of Pittsburgh, Medical Center, and Geriatric Research, Education, and Clinical Center, VA Pittsburgh Healthcare System, Pittsburgh, USA
5 Department of Geriatrics, Inselspital, Bern University Hospital, and University of Bern, Bern, Switzerland

6 Centre for Clinical Research, Haukeland University Hospital, Bergen, Norway

7 Department of Thoracic Medicine, Haukeland University Hospital, Bergen, Norway 


\section{Introduction}

Transcatheter aortic valve implantation (TAVI) is an established treatment for severe and symptomatic aortic stenosis in patients not eligible for open heart surgery, and it improves symptoms and increase life expectancy $[1,2]$. While indication for TAVI has expanded to also include younger and lower risk groups, the majority of TAVI patients are older and have significant comorbidity and frailty that contraindicated surgery. The Valve Academic Research Consortium-2 (VARC 2) consensus document recommends evaluation of independence in activity of daily living before the procedure as risk stratification [3]. However, few studies have focused on independence in activity of daily living as an outcome measure $[4,5]$.

Among older adults who are seriously ill, death might not be feared as the worse outcome. For many, reduced quality of life and functional or cognitive impairment [6,7], are relatively greater concerns. Dementia is highly prevalent in older adults [8] and is the leading cause of dependency in older age [9]. Shared decision-making is the favoured model for health care decisions, enhancing treatment choices to reflect patients' values and preferences [10]. However, the context of cognitive impairment or dementia makes it more difficult for TAVI candidates to participate in the decisionmaking process [11].

Thus, the aim of this study was to examine baseline frailty status including cognition and outcomes important to decision-making prior to TAVI.

\section{Methods}

\section{Study design}

This is a single-centre prospective, observational cohort study of 82 elective TAVI patients, with 2-year follow-up. Ninety-four patients were eligible for inclusion, five refused to participate and seven were not included due to logistical reasons. The patients were recruited consecutively from 2013 to 2015.

\section{Participants}

Patients $\geq 70$ years with symptomatic and severe aortic stenosis accepted for TAVI at Haukeland University Hospital in Western Norway were included. The hospital has a tertiary function for TAVI and serves a population of 1.1 million inhabitants. Severe aortic stenosis was defined by echocardiography according to the European Society of cardiology (ESC) guidelines [1]. Before accepting patients for TAVI, a heart team including interventional cardiologists, cardiac surgeons and imaging specialists, had declined them for surgical aortic valve replacement due to high risk. At the time of the study, there was no screening for frailty preceding the intervention, and the frailty score of the study patients was not known to the treatment team. The number of patients selected for conservative treatment is not known but suspected to be small. Nursing home patients and patients with severe dementia are rarely referred for valve intervention in Norway. Exclusion criteria were inability to understand or speak Norwegian.

\section{Procedural characteristics}

TAVI was delivered by different routes, seventy five (92\%) trans-femoral, five trans-subclavian and two with direct aortic access. Two different valves were used, the Medtronic Core Valve in 52 (63\%) and Boston Scientific LOTUS Valve in $30(37 \%)$ patients.

\section{Measurements}

\section{Baseline}

Mini-Mental Status Examination (MMSE) assesses cognition as a scale that ranges from 0 to 30 , with higher scores indicating better cognition [12]. The cut-off for normal cognitive function is usually set at 24 , with a sensitivity of 0.85 and a specificity of 0.90 for identifying anyone with dementia [13].

The research team developed an 8-item frailty scale [14]. The total score is calculated by adding different domain scores: cognition (MMSE $\geq 27=0$ points, MMSE $20-26=1$ point, MMSE $\leq 19=2$ points), instrumental activity of daily living (NEADL $\leq 43=1$ point), nutrition (BMI $<20.5=1$ point), modified SOF (low energy = 1 point, weight loss (reported, not measured weight loss; therefore, modified $)=1$ point, chair stand, not able $=1$ point) [15], Charlson Comorbidity Index ( $\geq 3=1$ point) [16], and psychological factors (HADS $\geq 15=1$ point) [17]. The score range from 0 to 9 , were 9 represents the frailest patients. Patients were classified frail if they scored $\geq 4$ points. This cut-off had a specificity of $80 \%$ and sensitivity of $60 \%$ at predicting 2 -year mortality for this population. In a receiver operating curve, the area under the curve was 0.81 (95\% confidence interval 0.71-0.90) [14]. 


\section{Baseline and 6 months:}

Nottingham Extended Activity of Daily living scale $(N E A D L)$ is a scale originally developed to assess activities of daily living (ADL) for stroke patients discharged to home, yet frequently used in non-stroke populations [18, 19]. The scale measures extended activities of daily living using a 22-item questionnaire, evaluating four different sections: mobility, kitchen, domestic and leisure. Patients are asked whether they perform the different activities, and the response categories are $0=$ not at all, $1=$ with help, $2=$ on my own with difficulty, $3=$ on my own. The different scores sums into a total score of 0 to 66 points, with higher scores indicating greater independence. A score $\leq 43$ indicates dependence [19]. One study of stroke patients reported a valid and reliable change if the NEADL improved or deteriorated by 4.9 points or more, and clinically important if the mean change score was in the range from 2.4 to 6.1 points after treatment [20].

The New York Heart Association (NYHA) classification describes patients' symptoms of heart failure [21] and has been applied to TAVI patients [3]. NYHA class I represents no symptoms of heart failure and no limitation of physical activity, while NYHA class IV represents symptoms of heart failure at rest. Despite limitations it's widely used both in research and clinical practice.

\section{Follow-up measurements}

Baseline NEADL and NYHA were assessed and then repeated at 6 months. Due to some patients living far from the hospital, we performed telephone interviews at 6 months, and MMSE and frailty testing were, therefore, not conducted. For the first 2 years, we recorded composite endpoints as recommended by the Valve Academic Research Consortium-2 (VARC-2) consensus document. We collected data of admission to long-term nursing homes for the first 2 years.

\section{Statistical analyses}

We present the data as means and standard deviations (SD), counts and percentages. Changes from baseline to 6 months are analysed using paired $t$-tests. There were little missing data so we have used complete case analysis and report the number of observations each analysis is based on. Statistical analysis was carried out in IBM SPSS Statistic 24 and R version 3.6.0 [22]. $p$ values $<0.05$ were considered statistically significant.

\section{Results}

\section{Baseline data}

\section{General characteristics}

We examined 82 patients with severe and symptomatic aortic stenosis, 39 (48\%) women. Mean age was 83 years (SD 4.7), two patients were over 90 years, the oldest 95 years old, and there were six patients under 75 years. Most patients (62\%) lived with their spouse. A majority (55\%) had only primary school, while $20 \%$ had a university degree.

\section{Geriatric characteristics}

Fifteen patients (18\%) had an MMSE score $<24$, suggesting they were cognitively impaired. One fifth of the patients had a low NEADL score $(\leq 43)$, implying dependence in at least one instrumental activity of daily living. As expected, NEADL and MMSE was correlated (Spearman's rho $=0.47$, $p<0.001)$. Eleven patients had a low BMI, however, 27 (33\%) reported weight loss last year. Charlson comorbidity index was $\geq 3$ in 36 (44\%) of the patients, demonstrating a high burden of comorbidity. Six (7\%) patients had a score $\geq 15$ on the Hospital Anxiety and Depression Scale; i.e., few patients had severe anxiety or depression. For 80 patients, baseline 8 -item frailty scale was calculated, and 14 patients $(18 \%)$ were defined as frail.

\section{Cardiovascular characteristics}

Logistic EuroSCORE [23] was below 10 (predicting low surgical risk) in 20 (24\%) and over 20 (high surgical risk) in $19(23 \%)$ of the patients. Almost half $(48 \%)$ of the patients had NYHA $\geq 3$ at baseline, indicating a significant burden of symptoms. Few patients $(11 \%)$ had a pacemaker before TAVI, and 26 (32\%) had atrial fibrillation at baseline (Table 1).

\section{Follow-up}

One patients was lost to follow-up at the telephone interview and three had died. For three patients, information was missing on whether they lived at home or in nursing home at 2-year follow-up. VARC 2 composite endpoint is presented in Table 2 , and endocarditis is separately presented in Table 3 with complementary data.

\section{Mortality and morbidity}

Two patients ( $2 \%$ ) died early ( $<30$ days), and one had a disabling stroke. At 1 year, four patients (5\%) had died and 
Table 1 Patient baseline characteristics $(n=82)$

\begin{tabular}{|c|c|c|}
\hline & Mean or count & SD or (percent) \\
\hline \multicolumn{3}{|l|}{ Characteristics } \\
\hline Age, years & 83 & 4.7 \\
\hline Women & 39 & $(48)$ \\
\hline Living alone & 29 & $(35)$ \\
\hline \multicolumn{3}{|l|}{ Education } \\
\hline Primary School & 45 & $(55)$ \\
\hline High School & 21 & $(26)$ \\
\hline University & 16 & $(20)$ \\
\hline \multicolumn{3}{|l|}{ Geriatric characteristics } \\
\hline \multicolumn{3}{|l|}{ Cognition } \\
\hline MMSE & 26.2 & 3.4 \\
\hline MMSE $\geq 24$ & 67 & $(82)$ \\
\hline MMSE 20-23 & 10 & $(12)$ \\
\hline MMSE $<20$ & 5 & (6) \\
\hline \multicolumn{3}{|l|}{ Activities of daily living } \\
\hline NEADL $\leq 43$ & $15 / 80$ & (19) \\
\hline \multicolumn{3}{|l|}{ Nutrition } \\
\hline BMI & 24.8 & 3.6 \\
\hline BMI $<20.5$ & 11 & (13) \\
\hline \multicolumn{3}{|l|}{$\mathrm{mSOF}$} \\
\hline Weight loss ${ }^{\mathrm{a}}$ & 27 & (33) \\
\hline Low energy & 32 & $(39)$ \\
\hline Unable to chair stand & 10 & $(12)$ \\
\hline \multicolumn{3}{|l|}{ Comorbidity } \\
\hline Charlson Comorbidity Index & 2.6 & 1.4 \\
\hline Charlson Comorbidity Index $\geq 3$ & 36 & $(44)$ \\
\hline \multicolumn{3}{|l|}{ Psychological factors } \\
\hline HADS $\geq 15$ & $6 / 81$ & (7) \\
\hline Frailty $^{\mathrm{b}}$ & $14 / 80$ & $(18)$ \\
\hline \multicolumn{3}{|l|}{ Cardiovascular characteristics } \\
\hline Logistic EuroSCORE & 15 & 7.9 \\
\hline Aortic Valve Area Index, $\mathrm{cm}^{2} / \mathrm{m}^{2}$ & 0.4 & 0.12 \\
\hline $\begin{array}{l}\text { Mean Aortic Valve gradient, } \\
\text { mmHg }\end{array}$ & 50 & 15 \\
\hline Left ventricular ejection fraction & 57 & 12 \\
\hline NYHA $\geq$ III & 39 & $(48)$ \\
\hline Previous myocardial infarction & 15 & $(18)$ \\
\hline CABG & 15 & $(18)$ \\
\hline Permanent pacemaker & 9 & $(11)$ \\
\hline Atrial fibrillation & 26 & $(32)$ \\
\hline Pulmonary hypertension & 27 & $(33)$ \\
\hline Cerebral Vascular Disease & 12 & $(15)$ \\
\hline \multicolumn{3}{|l|}{ Comorbidity } \\
\hline COPD & 19 & $(23)$ \\
\hline $\begin{array}{l}\text { Kidney failure; creatinine }>177 \\
\mu \mathrm{mol} / \mathrm{L}^{\mathrm{c}}\end{array}$ & 4 & $(5)$ \\
\hline
\end{tabular}

The total score is calculated by adding the different domain scores MMSE mini-mental status examination, NEADL Nottingham extended activities of daily living scale, $B M I$ body mass index, $S O F$ study of osteoporotic fractures, HADS hospital anxiety and depression scale
Table 1 (continued)

${ }^{a}$ Modified from the original SOF, with patient-reported weight loss past year, not measured as in the original index ( $\mathrm{mSOF}$ modified SOF)

b8-item geriatric assessment frailty scale. Missing information to calculate the scale in two patients, NYHA, New York Heart Association functional classification of heart failure, range from I to IV, most severe symptoms at IV. $C A B G$ coronary artery bypass grafting, $C O P D$ chronic obstructive pulmonary disease

${ }^{\mathrm{c}}$ As reported in the PARTNER study [2]; Creatinine $>2 \mathrm{mg} / \mathrm{dl}$ (177 $\mu \mathrm{mol} / \mathrm{L})$

$4(5 \%)$ had a disabling stroke. After 2 years, $6(7 \%)$ patients had died, five of cardiovascular and one of non-cardiovascular cause. Four patients lived in nursing homes. There were no new disabling stroke from one to 2 years. Six patients (7\%) had endocarditis during the first 2 years. Thirty-two patients (39\%) got a new pacemaker perioperative (during the hospital stay).

\section{Patient-reported outcome measures at 6 months}

\section{NEADL}

The NEADL score was available in 78 patients at 6 months. All patients were reached in person except for one, where the spouse provided information. For one patient, only NEADL at 6 months was available. There was no change in mean NEADL $(n=77)$ at baseline and 6 months with 54.2 (SD 11.5) and 54.5 (SD 10.3), respectively, mean difference $0.3(p=0.7)$. Even so, 13 patients $(17 \%)$ improved 5 points or more at the NEADL from baseline to 6 months, and 14 patients $(18 \%)$ deteriorated 5 points or more. We did not find an association between frailty status and deterioration in NEADL score. For example, the proportion of patients who deteriorated in NEADL score was similar in the frail and the non-frail group ( $42 \%$ and $55 \%$, respectively, $p=0.53$, Fisher's exact test).

\section{NYHA class}

After 6 months, the majority was in NYHA I (68\%), about a quarter were in NYHA II (27\%) and a few in NYHA III $(5 \%)$. No patients were in NYHA IV. Mean NYHA $(n=78)$ at baseline and 6 months was 2.5 (SD 0.6) and 1.4 (SD 0.6), respectively, a significant improvement $(p<0.001)$. Four patients had missing NYHA class at 6 months (three dead, one lost to follow-up) (Fig. 1). 
Table 2 Composite endpoints according to VARC $2^{\mathrm{a}}$ criteria

\begin{tabular}{|c|c|c|}
\hline & Total $(n=82)$ & Percent \\
\hline \multicolumn{3}{|l|}{ Device success } \\
\hline Absence of immediate procedural mortality ${ }^{\mathrm{b}}$ & 82 & 100 \\
\hline Correct positioning & 81 & 99 \\
\hline Intended performance of the prosthetic heart valve $\mathrm{c}^{\mathrm{c}}$ & 81 & 99 \\
\hline No moderate or severe prosthetic valve regurgitation ${ }^{\mathrm{d}}$ & 78 & 95 \\
\hline \multicolumn{3}{|l|}{ Early safety (at 30 days) } \\
\hline All-cause mortality & 2 & 2 \\
\hline All stroke(disabling or non-disabling) in hospital ${ }^{\mathrm{e}}$ & 1 & 1 \\
\hline Life-threatening or disabling bleeding & 4 & 5 \\
\hline Acute kidney injury-stage 2 or $3^{\mathrm{f}}$ & 2 & 2 \\
\hline Coronary artery obstruction requiring intervention & 1 & 1 \\
\hline Major vascular complication & 5 & 6 \\
\hline Valve-related dysfunction requiring intervention & 1 & 1 \\
\hline \multicolumn{3}{|l|}{ Clinical efficacy (30 days-2 years) } \\
\hline All-cause mortality & 4 & 5 \\
\hline All stroke(disabling or non-disabling) & 5 & 6 \\
\hline Requiring hospitalizations for valve-related symptoms or worsening congestive heart failure & 13 & 16 \\
\hline NYHA class III or IV ${ }^{g}$ & 4 & 5 \\
\hline \multicolumn{3}{|l|}{ Time-related valve safety } \\
\hline \multicolumn{3}{|l|}{ Structural valve deterioration } \\
\hline $\begin{array}{l}\text { Valve-related dysfunction (mean aortic valve gradient } \geq 20 \mathrm{mmHg} \text { ) and/ or moderate or severe prosthetic } \\
\text { valve regurgitation }\end{array}$ & $15 / 81$ & 19 \\
\hline Requiring repeat procedure (TAVI or SAVR) & 1 & 1 \\
\hline Prosthetic valve endocarditis ${ }^{\mathrm{f}}$ & 6 & 7 \\
\hline Trombo-embolic events (eg stroke) & 6 & 7 \\
\hline $\begin{array}{l}\text { VARC bleeding (life threatening/disabling bleeding or major bleeding), unless clearly unrelated to valve } \\
\text { therapy (e.g. trauma) }\end{array}$ & 14 & 17 \\
\hline
\end{tabular}

SAVR Surgical aortic valve replacement, TAVI transcatheter aortic valve implantation, NYHA New York Heart Association

${ }^{a}$ The Valve Academic Research Consortium (VARC)-2 consensus document (see references)

${ }^{\mathrm{b}}$ Immediate or consequent death $\leq 72 \mathrm{~h}$ post-procedure

${ }^{\mathrm{c}}$ No prosthesis-patient mismatch. Mean aortic valve gradient $<20 \mathrm{mmHg}$ or peak velocity $<3 \mathrm{~m} / \mathrm{s}$

${ }^{\mathrm{d}}$ After TAVI procedure at index hospitalization

${ }^{\mathrm{e}}$ Assessment of stroke at index. All strokes verified by CT/MRI

${ }^{\mathrm{f}}$ Evaluation of acute kidney injury is based on serum creatinine, we miss data on urine output

${ }^{\mathrm{g}} \mathrm{NYHA}$ at 6 months

${ }^{\text {h}}$ Four patients had new paravalvular leak or vegetation on the aortic valve

\section{Discussion}

This prospective observational study of 82 patients documents symptom improvement and maintenance of activities of daily living 6 months after TAVI. They had low mortality and most patients lived in their own home 2 years after TAVI. At baseline, $18 \%$ had an MMSE score, indicating cognitive impairment or dementia. We found a higher frequency of endocarditis than expected. According to the basic principles of shared decisions-making, balanced information regarding risks and benefits, and exploring patients' values and goals are important. Physicians should be aware that patients' cognitive impairment or dementia might affect the ability to participate in the decision-making process and give an informed consent.

Mortality at one (5\%) and 2 years (7\%) after TAVI was low in this cohort, where mean age is over 80 years and there is a substantial burden of comorbidity and frailty. We found a substantial improvement in NYHA class from baseline to 6 months. Based on the improvement of symptoms we expected to find an improvement in NEADL. However, we found no change in mean NEADL. There was a variation on an individual level. Some patients improved their independence and others deteriorated, although for most patients, the 
Table 3 Infective endocarditis first 2 years after TAVI

\begin{tabular}{|c|c|c|c|c|c|c|c|}
\hline TAVI valve & $\begin{array}{l}\text { Age at } \\
\text { TAVI and } \\
\text { gender }^{\mathrm{a}}\end{array}$ & $\begin{array}{l}\text { Days after } \\
\text { TAVI, positive } \\
\text { blood culture }\end{array}$ & $\begin{array}{l}\text { Bacteria (4/4 } \\
\text { blood cultures) }\end{array}$ & Dukes criteria $^{\mathrm{b}}$ & $\begin{array}{l}\text { Outcome two } \\
\text { year }\end{array}$ & TTE and TEE & Pacemaker device \\
\hline Lotus $27 \mathrm{~mm}$ & $86 \mathrm{y}, \mathrm{F}$ & 49 & $\begin{array}{l}\text { Stafylococcus } \\
\text { aureus }\end{array}$ & $\begin{array}{l}1 \text { Major }+3 \\
\text { minor }\end{array}$ & Dead $^{c}$ & $\begin{array}{l}\text { No vegetation or } \\
\text { PVL }\end{array}$ & $\begin{array}{l}\text { PM, } 1 \text { day after } \\
\text { TAVI }\end{array}$ \\
\hline $\begin{array}{l}\text { Core valve } 31 \\
\mathrm{~mm}\end{array}$ & $77 \mathrm{y}, \mathrm{M}$ & 190 & $\begin{array}{l}\text { Streptococcus } \\
\text { salvarius }\end{array}$ & $\begin{array}{l}2 \text { Major }+2 \\
\text { minor }\end{array}$ & Alive & $\begin{array}{c}\text { Aortic valve } \\
\text { vegetation }\end{array}$ & $\begin{array}{l}\text { CRT-D , } 3 \text { months } \\
\text { before TAVI }\end{array}$ \\
\hline $\begin{array}{l}\text { Core valve } 31 \\
\mathrm{~mm}\end{array}$ & $80 \mathrm{y}, \mathrm{M}$ & 380 & $\begin{array}{l}\text { Enterococcus } \\
\text { faecalis }\end{array}$ & $\begin{array}{l}1 \text { Major + } 3 \\
\text { minor }\end{array}$ & Alive & New aortic PVL & $\begin{array}{l}\text { CRT-P, } 2 \text { months } \\
\text { after TAVI }\end{array}$ \\
\hline $\begin{array}{l}\text { Core valve } 29 \\
\text { mm }\end{array}$ & 79 y, M & 407 & $\begin{array}{l}\text { Streptococcus } \\
\text { sanguinis }\end{array}$ & $\begin{array}{l}1 \text { Major + } 3 \\
\text { minor }\end{array}$ & Alive & New aortic PVL & No \\
\hline $\begin{array}{l}\text { Core valve } 31 \\
\mathrm{~mm}\end{array}$ & $77 \mathrm{y}, \mathrm{M}$ & 448 & $\begin{array}{l}\text { Stafylococcus } \\
\text { aureus }\end{array}$ & $\begin{array}{l}2 \text { Major }+4 \\
\text { minor }\end{array}$ & Dead $^{\mathrm{d}}$ & $\begin{array}{c}\text { Aortic valve } \\
\text { vegetation }\end{array}$ & $\begin{array}{r}\text { CRT-P, } 1 \text { year } \\
\text { before TAVI }\end{array}$ \\
\hline $\begin{array}{l}\text { Core valve } 31 \\
\mathrm{~mm}\end{array}$ & $80 \mathrm{y}, \mathrm{M}$ & 528 & $\begin{array}{l}\text { Streptococcus } \\
\quad \text { oralis }\end{array}$ & $\begin{array}{l}1 \text { Major + } 1 \\
\text { minor }\end{array}$ & Alive & $\begin{array}{l}\text { No vegetation or } \\
\text { PVL }\end{array}$ & $\begin{array}{l}\text { PM, } 1 \text { day after } \\
\text { TAVI }\end{array}$ \\
\hline
\end{tabular}

TTE transthoracic echocardiography, TEE trans-oesophageal echocardiography, $P V L$ para valvular leak, $P M$ pacemaker, $C R T-P / D$ coronary resynchronisation therapy with cardiac defibrillator (D) or pacemaker $(\mathrm{P})$

${ }^{\mathrm{a}} y$ years, $M$ male, $F$ female

${ }^{\mathrm{b}}$ All meet criteria for definite infective endocarditis (IE) except the last patient who has a possible IE. All patients had trans-femoral access for TAVI

${ }^{c}$ Died five months after diagnosed with IE

${ }^{\mathrm{d}}$ Died one month after diagnosed with IE

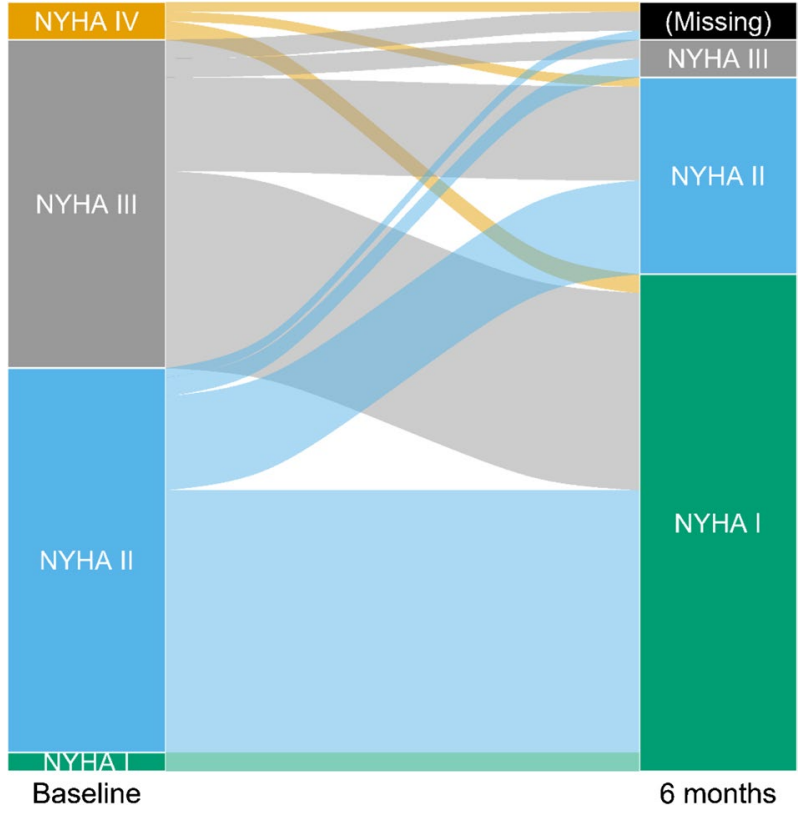

Fig. 1 Individual changes in NYHA class from baseline $(n=82)$ to 6 months $(n=78)$. The height of each bar is proportional to the number of patients with the corresponding NYHA class, and the width of the ends of each flow line is proportional to the number of patients with the given pattern of change of NYHA class

change in NEADL was minor. Other factors, like frailty and dementia, probably have more impact on the level of independence than the aortic stenosis per se [4], and 6 months follow-up is probably too short to establish deterioration due to other causes. There was no difference between the frail and robust patients regarding change in NEADL from baseline to 6 months.

At baseline, 15 patients had an MMSE below 24, indicating possible cognitive impairment or dementia [13]. Five patients had an MMSE less than 20, which increases the probability of incapacity, and likely reduces their power of judgement during the decision-making processes before TAVI [11]. Several studies have suggested that a low MMSE score at baseline predicts poor outcomes after TAVI [4, 24]. However, there are also studies demonstrating cognitive improvement after TAVI when impairment is caused by the aortic stenosis itself [25]. For patients with established dementia, surviving to end stage dementia might not be what the patient would choose autonomously. These are difficult issues to discuss with patients with dementia and their families, both due to patients' anosognosia (a physiological damage to the brain, where patients have no awareness of their disease) [26], and also health care professionals' fear of patients losing hope when focusing on the deterioration and increased dependence expected after a diagnosis of dementia [27]. It is important to point out that an MMSE $<24$ is not diagnostic of dementia, and sensitivity and specificity for MMSE cutoffs in a TAVI population, might be different than in the general population. Suspicion of dementia should, therefore, lead to further investigations. 
We found a higher frequency of infective endocarditis (IE) than expected. In a recent meta-analysis with a mean follow-up at 3.4 years, the overall incidence of IE in TAVI was $2.0 \%$ [28]. In the present study, five of six patients with IE had a pacemaker or an ICD, which might be associated with an increased risk of IE [29]. Several single-centre studies finding higher incidences suggests that IE is underreported in large studies and registries [30, 31]. Diagnosing endocarditis is challenging, and the presentation might be uncharacteristic since the patients are old with comorbidities [28]. As endocarditis can occur later on, longer follow-up than 1 year seems important. Antibiotic prophylaxis during the TAVI procedure were administered to all patients. General practitioners were informed routinely on discharge about the risk of endocarditis and indications for prophylaxis.

Prior to TAVI, patients need to be informed of expected NYHA class improvement, survival benefit and maintenance of activities of daily living. Rare and severe complications, like death, stroke and infectious endocarditis, should also be part of the pre- TAVI discussion with the patient. Old patients with substantial comorbidity need to be informed that TAVI will not solve all their health problems. After the study period, written information about the procedure and risks and benefits was developed and administered to patients as part of the decision-making process. Our findings may be used when developing and improving decision aids for this treatment in older adults.

\section{Strengths of the study}

All hospitals in Western Norway use the same electronic medical records and VARC-2 endpoints are complete with no patients lost to follow-up. All deaths are automatically registered in the patients' electronic journal. The same investigator (ES) performed the assessment at baseline and 6 months, increasing reliability.

\section{Limitations of the study}

This is a single centre study performed in the early era of TAVI and some of the results might not be transferable due to improvement of equipment, better patient selection and training of the interventional cardiologists performing the procedure. Most patients were independent before TAVI, and minor (nevertheless important to patients) improvements might not be revealed by the NEADL questionnaire. Due to the small sample size, it was not possible to analyse whether specific subgroups improved or deteriorated in NEADL. We performed only telephone interviews at 6 months, preventing us from assessing MMSE and frailty at follow-up. We assume that living in their own home 2 years after TAVI reflects independence of activities of daily living, however, we cannot exclude that some patients living at home were in need of extended care.

\section{Conclusion}

TAVI patients had symptom improvement and maintenance of activity of daily living at 6 months. They had low mortality, and most patients lived in their own home 2 years after TAVI. Severe complications, like death, stroke and endocarditis, occurred. Balanced information regarding these risks and benefits is needed to ensure informed consent prior to the procedure, and our findings may be used to develop and improve decision aids assisting this process. Clinicians should be aware that some patients have cognitive impairment before TAVI that might affect their power of judgement and decision-making.

Acknowledgements Open Access funding provided by University of Bergen. We would like to thank the participants of this study.

Funding This work was supported by Grieg Foundation; and the Department of Heart Disease, Haukeland University Hospital, Bergen, Norway. The funding sources had no influence on the study.

\section{Compliance with ethical standards}

Conflict of interest On behalf of all authors, the corresponding author states that there is no conflict of interest.

Human and animal rights statement All procedures performed in the study were in accordance with the ethical standards of the institution and the national research committee and with the 1964 Helsinki declaration and it's later amendments. The regional Committee for medical research ethics approved the study (REK 2013/1310).

Informed consent Written, informed consent was obtained from all participants.

Open Access This article is licensed under a Creative Commons Attribution 4.0 International License, which permits use, sharing, adaptation, distribution and reproduction in any medium or format, as long as you give appropriate credit to the original author(s) and the source, provide a link to the Creative Commons licence, and indicate if changes were made. The images or other third party material in this article are included in the article's Creative Commons licence, unless indicated otherwise in a credit line to the material. If material is not included in the article's Creative Commons licence and your intended use is not permitted by statutory regulation or exceeds the permitted use, you will need to obtain permission directly from the copyright holder. To view a copy of this licence, visit http://creativecommons.org/licenses/by/4.0/. 


\section{References}

1. Baumgartner H, Falk V, Bax JJ et al (2017) 2017 ESC/EACTS Guidelines for the management of valvular heart disease. Eur Heart J 38: 2739-2791

2. Leon MB, Smith CR, Mack M et al (2010) Transcatheter aortic-valve implantation for aortic stenosis in patients who cannot undergo surgery. N Engl J Med 363: 1597-1607

3. Kappetein AP, Head SJ, Genereux P et al (2012) Updated standardized endpoint definitions for transcatheter aortic valve implantation: the Valve Academic Research Consortium- 2 consensus document (VARC-2). Eur J Cardiothorac Surg 42: S45-60

4. Schoenenberger AW, Stortecky S, Neumann S et al (2013) Predictors of functional decline in elderly patients undergoing transcatheter aortic valve implantation (TAVI). Eur Heart J 34: 684-692

5. Eide LS, Ranhoff AH, Fridlund B et al (2016) Delirium as a predictor of physical and cognitive function in individuals aged 80 and older after transcatheter aortic valve implantation or surgical aortic valve replacement. J Am Geriatr Soc 64: 1178-1186

6. Fried TR, Bradley EH, Towle VR et al (2002) Understanding the treatment preferences of seriously ill patients. N Engl J Med 346: 1061-1066

7. Yellen SB, Cella DF, Leslie WT (1994) Age and clinical decision making in oncology patients. J Natl Cancer Inst 86: 1766-1770

8. Satizabal CL, Beiser AS, Chouraki V et al (2016) Incidence of dementia over three decades in the Framingham heart study. $\mathrm{N}$ Engl J Med 374: 523-532

9. World Health Organization and Alzheimer's Disease International. Dementia: a public health priority. 2012 [cited $2019 \mathrm{Sep}$ 25]; 112]. https://apps.who.int/iris/bitstream/handle/10665/75263 19789241564458_eng.pdf.

10. Elwyn G, Frosch D, Thomson R et al (2012) Shared decision making: a model for clinical practice. J Gen Intern Med 27: 1361-1367

11. Sessums LL, Zembrzuska H, Jackson JL (2011) Does this patient have medical decision-making capacity? JAMA 306: 420-427

12. Folstein MF, Folstein SE, McHugh PR (1975) "Mini-mental state". A practical method for grading the cognitive state of patients for the clinician. J Psychiatr Res 12: 189-198

13. Creavin ST, Wisniewski S, Noel-Storr AH et al (2016) MiniMental State Examination (MMSE) for the detection of dementia in clinically unevaluated people aged 65 and over in community and primary care populations. Cochrane Database Syst Rev 13: CD011145

14. Skaar E, Eide LSP, Norekval TM et al (2019) A novel geriatric assessment frailty score predicts 2-year mortality after transcatheter aortic valve implantation. Eur Heart J Qual Care Clin Outcomes 5: 153-160

15. Ensrud KE, Ewing SK, Taylor BC et al (2008) Comparison of 2 frailty indexes for prediction of falls, disability, fractures, and death in older women. Arch Intern Med 168: 382-389

16. Charlson ME, Pompei P, Ales KL et al (1987) A new method of classifying prognostic co-morbidity in longitudinal-studiesdevelopment and validation. J Chronic Dis 40: 373-383

17. Zigmond AS, Snaith RP (1983) The hospital anxiety and depression scale. Acta Psychiatr Scand 67: 361-370
18. Lincoln NB, Gladman JR (1992) The extended activities of daily living scale: a further validation. Disabil Rehabil. [Research Support, Non-U.S. Gov't] 14: 41-43

19. Kristjansson SR, Nesbakken A, Jordhoy MS et al (2010) Comprehensive geriatric assessment can predict complications in elderly patients after elective surgery for colorectal cancer: a prospective observational cohort study. Crit Rev Oncol Hematol 76: 208-217

20. Wu CY, Chuang LL, Lin KC et al (2011) Responsiveness, minimal detectable change, and minimal clinically important difference of the Nottingham Extended Activities of Daily Living Scale in patients with improved performance after stroke rehabilitation. Arch Phys Med Rehabil 92: 1281-1287

21. The Criteria Committee for the New York Heart Association (1964) Nomenclature and criteria for diagnosis of diseases of the heart and blood vessels. Little Brown, Boston

22. R Core Team (2019) Vienna, Austria [cited 2019]. R: A language and environment for statistical computing]. https://www.r-proje ct.org/

23. Roques F, Michel P, Goldstone AR et al (2003) The logistic EuroSCORE. Eur Heart J 24: 881-882

24. Kim DH, Afilalo J, Shi SM et al (2019) Evaluation of changes in functional status in the year after aortic valve replacement. JAMA Intern Med 179: 383-391

25. Schoenenberger AW, Zuber C, Moser A et al (2016) Evolution of cognitive function after transcatheter aortic valve implantation. Circ Cardiovasc Interv 9:e00359. https://doi.org/10.1161/CIRCI NTERVENTIONS.116.003590

26. Salmon E, Perani D, Herholz K et al (2006) Neural correlates of anosognosia for cognitive impairment in Alzheimer's disease. Hum Brain Mapp 27: 588-597

27. Marzanski M (2000) On telling the truth to patients with dementia. West J Med 173: 318-323

28. Ando T, Ashraf S, Villablanca PA et al (2019) Meta-analysis comparing the incidence of infective endocarditis following transcatheter aortic valve implantation versus surgical aortic valve replacement. Am J Cardiol 123: 827-832

29. Kolte D, Goldsweig A, Kennedy KF et al (2018) Comparison of incidence, predictors, and outcomes of early infective endocarditis after transcatheter aortic valve implantation versus surgical aortic valve replacement in the United States. Am J Cardiol 122: 2112-2119

30. Puls M, Eiffert H, Hunlich M et al (2013) Prosthetic valve endocarditis after transcatheter aortic valve implantation: the incidence in a single-centre cohort and reflections on clinical, echocardiographic and prognostic features. EuroIntervention 8: 1407-1418

31. Rodriguez-Vidigal FF, Nogales-Asensio JM, Calvo-Cano A et al (2019) Infective endocarditis after transcatheter aortic valve implantation: contributions of a single-centre experience on incidence and associated factors. Enferm Infecc Microbiol Clin 37:428-434. https://doi.org/10.1016/j.eimc.2018.09.009

Publisher's Note Springer Nature remains neutral with regard to jurisdictional claims in published maps and institutional affiliations. 